\title{
Enhanced electrocatalytic hydrogen evolution reaction: supramolecular assemblies of metalloporhyrins on glassy carbon electrodes
}

\author{
Camila Canales ${ }^{\text {a }}$, Felipe Varas-Concha ${ }^{\mathrm{b}}$, Thomas E. Mallouk ${ }^{\mathrm{c} *}$ and Galo Ramírez ${ }^{\mathrm{a} *}$ \\ ${ }^{a}$ Facultad de Quimica, Departamento de Quimica Inorgánica, Pontificia Universidad Católica de Chile, Av. Vicuña \\ Mackenna 4860, casilla 306, correo 22, Santiago,Chile.gramirezj@uc.cl \\ ${ }^{b}$ Facultad de Ingeniería, Departamento de Ingeniería Química y Bioprocesos, Pontificia Universidad Católica de Chile. \\ ${ }^{c}$ Departments of Chemistry, Biochemistry and Molecular Biology, and Physics, The Pennsylvania State University, \\ University Park, PA 16802 USA.tem5@psu.edu
}

\begin{abstract}
Chemically modified electrodes formed by $\pi$-stacking of metalloporphyrins provide a stable and efficient electrocatalytic system for the hydrogen evolution reaction at $\mathrm{pH}$ 7.0. Metalloporphyrins $\mathrm{M}-\mathrm{OEP}(\mathrm{M}=\mathrm{Co}(\mathrm{II})$, $\mathrm{Cu}(\mathrm{II}), \mathrm{Zn}(\mathrm{II}), \mathrm{Ru}(\mathrm{II}), \mathrm{Fe}(\mathrm{III})$ and $\mathrm{Ni}(\mathrm{II}), \mathrm{OEP}=2,3,7,8,12,13,17,18$-Octaethyl-21H,23H-porphine) were deposited on glassy carbon electrodes that had been previously modified by using $\mathrm{NaOH}$ and 4aminopyridine, which served as a bridging molecule between the metalloporphyrins and the electrode surface. Different supramolecular architectures, as revealed by AFM and SEM, were obtained with bare and oxidized glassy carbon electrode surfaces. The most active systems were those obtained with $\mathrm{Co}$ (II) and $\mathrm{Cu}(\mathrm{II})$ porphyrins. Raman spectra showed the presence of the linking molecules and metalloporphyrins in the electrocatalytic metalloporphyrin films.
\end{abstract}

Keywords: Hydrogen evolution reaction, metalloporphyrins, glassy carbon electrodes, supramolecular system, graphene.

\section{INTRODUCTION}

A major issue in the development of renewable energy resources is the production of hydrogen $\left(\mathrm{H}_{2}\right)$ from sources other than fossil fuels. Currently, the most economical process for hydrogen production is steam reforming of natural gas, which entails the production of $\mathrm{CO}_{2}$ as a byproduct [1,2]. Water electrolysis is recognized as an alternative, albeit expensive, method to obtain $\mathrm{H}_{2}$, since it provides a link between electrical energy and hydrogen, a high-energy-density fuel and a versatile energy carrier [3-5]. The hydrogen evolution reaction (her) is the cathode reaction in water electrolysis and is one of the main determinants of cost and efficiency. Traditionally, the her has been catalyzed in membrane-based electrolyzers by precious metal catalysts, such as $\mathrm{Pt}$, which are rare, expensive, and easily poisoned. More recently, electrocatalysts derived from earth-abundant transition metals such as $\mathrm{Fe}, \mathrm{Co}$ and $\mathrm{Ni}$ have been investigated as promising alternatives in both acidic and alkaline electrolytes [6-11]. It is well documented that aza-macrocyclic compounds, such as metalloporhyrins, can catalyze many reactions due to their redox activity, chemical stability, and planar structure, among other characteristics [12]. A number of discrete molecular cobalt and nickel complexes have been found to electrocatalytically reduce water to hydrogen with high Faradaic yields [13-16], but most of these electrocatalysts have been studied in non-aqueous solutions. We show here that some of these materials can be used to modify electrodes and produce cathodes with high catalytic activity for hydrogen evolution from water.

In this work we have modified glassy carbon electrodes with commercial octaethylporphyrins (M-OEP, M = $\mathrm{Co}(\mathrm{II}), \mathrm{Cu}(\mathrm{II}), \mathrm{Zn}(\mathrm{II}), \mathrm{Ru}(\mathrm{II}), \mathrm{Fe}(\mathrm{III})$ and $\mathrm{Ni}(\mathrm{II})$ ) in order to study their electrocatalytic properties in the aqueous hydrogen evolution reaction. Glassy carbon electrodes were covalently modified by surface oxidation 
and by reaction with 4-aminopyridine (4AP) with the aim of anchoring the catalytic molecules by coordination to the metal center of the porphyrin. This modification enables the deposition of molecular assemblies that are formed by $\pi$-stacking. In this supramolecular architecture, a synergic effect is expected since $\pi$-stacking provides good electronic communication between the electrode and catalytic sites in the metalloporphyrins. The morphology of these electrode films was characterized by Atomic Force Microscopy (AFM) and Scanning Electron Microscopy (SEM), and the structure of the supramolecular aggregates was studied by Raman spectroscopy. The Raman spectra verify the existence of the covalent linkages between the electrode surface and metalloporphyrins through the 4AP molecule and oxidized groups.

\section{EXPERIMENTAL}

\subsection{Chemicals and Solutions}

$\mathrm{KCl}, \mathrm{NaOH}$ and $\mathrm{Cl}_{2} \mathrm{CH}_{2}$ were obtained from Merck as analytical grade reagents. Deionized water was obtained from a Millipore-Q system $(18.2 \mathrm{M} \Omega \cdot \mathrm{cm})$. Argon (99.99 \% pure) and dioxygen gas were purchased from AGA, Chile. Metalloporphyrins (2,3,7,8,12,13,17,18-Octaethyl-21H,23H-porphine cobalt(II), 2,3,7,8,12,13,17,18-Octaethyl-21H,23H-porphine $\quad$ copper(II), $\quad 2,3,7,8,12,13,17,18$-Octaethyl-21H,23Hporphine zinc(II), 2,3,7,8,12,13,17,18-Octaethyl-21H,23H-porphine ruthenium(II) carbonyl, 2,3,7,8,12,13,17,18-Octaethyl-21H,23H-porphine iron(III) chloride and 2,3,7,8,12,13,17,18-Octaethyl$21 \mathrm{H}, 23 \mathrm{H}$-porphine nickel(II)) and 4AP, were all purchased from Sigma-Aldrich Chile.

\subsection{Instrumentation}

Cyclic voltammetry studies were performed on a $\mathrm{CH}$ Instruments $750 \mathrm{D}$ potentiostat galvanostat. The conventional three-electrode system consisted of a glassy carbon (GC) working electrode $\left(0.071 \mathrm{~cm}^{2}\right)$, $\mathrm{Ag} / \mathrm{AgCl}(3 \mathrm{M} \mathrm{KCl})$ reference electrode, and a platinum wire counter electrode. Gold electrodes were used in parallel experiments in order to obtain Raman spectra.

For electrolysis experiments, an electrolysis cell was used. A conventional three-electrode system was used, consisting of a glassy carbon (GC) working electrode $\left(1.7 \mathrm{~cm}^{2}\right), \mathrm{Ag} / \mathrm{AgCl}(3 \mathrm{M} \mathrm{KCl})$ reference electrode, and a platinum wire counter electrode. Gas chromatography experiments were carried out by using a DANIInstruments ${ }^{\circledR}$ Gas Chromatograph.

Atomic Force Microscopy (AFM) studies were done by using an Innova ${ }^{\circledR}$ Atomic Force Microscope. Scanning Electron Microscopy (SEM) studies were performed in a Nova NanoSEM ${ }^{\mathrm{TM}} 630$ and Raman spectra were obtained by using a Renishaw microRaman instrument.

\subsection{Preparation of modified electrodes and analysis}

The GC electrode was polished to a mirror finish on a felt pad using alumina slurries $(3 \mu \mathrm{m})$. Then, it was cleaned by immersion in an ultrasonic bath for 60 seconds, and finally stabilized by cycling the potential between $-0.7 \mathrm{~V}$ and $0.7 \mathrm{~V}$ in a solution of $0.1 \mathrm{M} \mathrm{NaOH}$ under Ar atmosphere.

Covalently modified electrodes were obtained as reported previously using $\mathrm{NaOH}$ and $4 \mathrm{AP}[10,17]$. Then, they were submerged in a $0.2 \mathrm{mM}$ solution of metalloporphyrin, M-OEP ( $\mathrm{M}=\mathrm{Co}(\mathrm{II}), \mathrm{Cu}(\mathrm{II}), \mathrm{Zn}$ (II), $\mathrm{Ru}(\mathrm{II})$, $\mathrm{Fe}(\mathrm{III})$ and $\mathrm{Ni}$ (II)) dissolved in $\mathrm{CH}_{2} \mathrm{Cl}_{2}$ for 20 minutes at room temperature (In) and for 60 minutes under reflux (R). The electrodes were then dried at room temperature for $1 \mathrm{~min}$. 
All the modified electrodes were analyzed in a phosphate buffer solution $\left(\mathrm{H}_{2} \mathrm{PO}_{4}{ }^{-} / \mathrm{HPO}_{4}{ }^{2-} 0.066 \mathrm{~mol} \mathrm{~L}^{-1}\right.$ saturated with $\mathrm{Ar}$ ) by cycling the potential between $0.0 \mathrm{~V}$ and $-1.8 \mathrm{~V}$. Controlled-potential electrolyses at -1.1 $\mathrm{V}$ were conducted in stirred $0.066 \mathrm{~mol} \mathrm{~L}^{-1}$ phosphate buffer solutions, $\mathrm{pH}$ 7.0. The faradaic yield of $\mathrm{H}_{2}$ was determined by sampling the headspace of the electrolysis cell after $4 \mathrm{~h}$ and analyzing the sample by gas chromatography.

Gold-coated glass slides (EMF Corp. CA134, $100 \mathrm{~nm}$ Au deposited onto a $5 \mathrm{~nm} \mathrm{Cr}$ adhesion layer on float glass) were used as gold electrodes. These electrodes were cleaned with acetone in ultrasonic bath for 40 minutes before each modification, whereas graphene electrodes were used as received. Both substrates were stabilized on a $0.1 \mathrm{M} \mathrm{NaOH}$ solution by cycling the potential between -1.0 and $1.0 \mathrm{~V}$, and -0.7 and $0.7 \mathrm{~V}$, for gold and graphene electrodes respectively.

Raman spectra were obtained by modifying gold and graphene electrodes, following the same procedure used for glassy carbon electrodes. These substrates were used since GC is not appropriate for Raman studies. Laser excitation wavelengths of $786 \mathrm{~nm}$ (for studying bonding of 4AP to the electrode) and $532 \mathrm{~nm}$ (for supramolecular porphyrin complexes) were used.

Morphological studies were done by using AFM and SEM. In these studies, all samples were analyzed on glassy carbon substrates. Tapping mode was used in all AFM experiments.

\section{RESULTS AND DISCUSSION}

\subsection{Voltammetric measurements}

In order to study the her, glassy carbon electrodes modified by 4AP were prepared in $\mathrm{NaOH} / 4 \mathrm{AP}$ solutions as previously reported [17]. Then, two systems covalently modified are obtained: GC ox and GC + 4AP. In the first case, oxidized groups are formed on the GC surface [17,18] in order to serve as anchoring group between the electrode and the metalloporphyrin. Each metalloporhyrin studied was deposited via immersion (In) and reflux (R) (figures S1, S2 and S3, Supporting Information), with the aim of comparing the effects of the bridging molecule, the catalytic metal center, and the method of electrode modification. The bridging molecule is covalently bonded to the carbon electrode surface and, at the same time, is coordinated to the metal center of the complex, which generates the first layer of complexes bonded to the electrode surface through the bridge molecule. On this first layer, more layers of complexes are stacked by $\pi$ interactions that finally form a system with supramolecular characteristics [19]. Figure 1 shows the voltammetric responses of the most active systems for the her after 10 cycles. The most active systems are those generated via reflux (R) with $\mathrm{Co}(\mathrm{II})$ and $\mathrm{Cu}(\mathrm{II})$ complexes (figure S4, Supporting Information) over the ones generated by immersion and other metalloporphyrins. By comparing the (In) and (R) electrodes, it is evident that the method of modification strongly influences the electrocatalytic response towards the her (see supporting information).

By using reflux as the method of modification, we expected to generate thicker assemblies or aggregates of complexes that are held together by $\pi$ interactions. These architectures would promote electronic communication between the electrode and the catalytic metal centers in the metalloporphyrin complexes. The systems $\mathrm{GC}+4 \mathrm{AP}+\mathrm{Co}(\mathrm{II}) \mathrm{OEP}$ and $\mathrm{GC}$ ox $+\mathrm{Cu}(\mathrm{II}) \mathrm{OEP}$ have higher electroactivity than the other metalloporphyrins studied, providing evidence of the effect of the metal center. These metals are electron-rich atoms and their electronic configuration facilitates the charge transfer processes in order to reduce $\mathrm{H}^{+}$in aqueous media to produce $\mathrm{H}_{2}$. 
The obtained systems are as active as other $3 \mathrm{~d}$ transition metal macrocyclic catalysts previously reported [15], and in comparison to earlier studies $[16,20]$, the responses are better in terms of potential and current, considering the $\mathrm{pH}$ of the medium. These previous studies show that, as the $\mathrm{pH}$ is increased, the activity of the catalyst at constant overpotential decreases. Thus, a higher overpotential is required to reduce $\mathrm{H}^{+}$near neutral $\mathrm{pH}$, and a more complex system is required to electrocatalyze the her because the reduction of the redox couple $\mathrm{Co}^{\mathrm{II}}-\mathrm{Co}^{\mathrm{I}}$ occurs at higher overpotential. The metalloporphyrin films described here are simple to prepare, and are electroactive at $\mathrm{pH}$ 7.0.

As noted above, the refluxing method results in the formation of metalloporphyrin aggregates through $\pi$ stacking, and covalent anchoring to the electrode is expected to impart stability and directionality of electron flow in the system. In order to test this hypothesis, the voltammetric responses of the systems generated from $\mathrm{Co}(\mathrm{II})$ and $\mathrm{Cu}(\mathrm{II})$ complexes, in presence and absence of the 4AP anchoring molecule were studied, and the results are shown in Figure 2. These comparisons confirm that substantial differences in electrocatalytic activity occur depending on the presence of the 4AP molecule and the method of electrode modification.

For both $\mathrm{Co}(\mathrm{II})$ and $\mathrm{Cu}(\mathrm{II})$ complexes, we observe an electroactivity enhancement when the electrode is modified with $4 \mathrm{AP}$ and when the film is deposited by the reflux method. These observations suggest that these new systems have a supramolecular character, due to the bridge molecule that orients the assemblies (by the coordination of the metal center which occupies an axial free position) and due to the reflux, which facilitates the aggregation of porphyrin films on the electrode surface $[19,21,22]$.

A Tafel slope greater than $100 \mathrm{mV}$ per decade was expected since a Tafel slope of about $160 \mathrm{mV}$ per decade in aqueous electrolyte at neutral $\mathrm{pH}$ has been previously observed with related catalysts [23]. The Tafel slope at high negative overpotentials is consistent with her that proceeds via a Volmer-Heyrovsky mechanism [20,21,24], as follows:

$$
\begin{array}{lll}
\mathrm{M}+\mathrm{H}_{3} \mathrm{O}^{+}+\mathrm{e}^{-} & \rightarrow & \mathrm{M}-\mathrm{H}_{a d s}+\mathrm{H}_{2} \mathrm{O} \\
\mathrm{M}-\mathrm{H}_{a d s}+\mathrm{H}_{3} \mathrm{O}^{+} & \rightarrow & \mathrm{M}+\mathrm{H}_{2}+\mathrm{H}_{2} \mathrm{O} \\
\mathrm{M}-\mathrm{H}_{a d s}+\mathrm{M}-\mathrm{H}_{a d s} & \rightarrow & \mathrm{H}_{2}+2 \mathrm{M}
\end{array}
$$

Table 1 shows the calculated values of Tafel slopes corresponding to each obtained system. In every case, the values are around $100 \mathrm{mV}$ per decade, which is consistent of what is discussed before. The amount of metalloporphyrin deposited on the electrodes is also considered.

Table 1. Tafel slopes calculated for GC $+4 \mathrm{AP}+\mathrm{Co}(\mathrm{II}) \mathrm{OEP}, \mathrm{GC}$ ox $+\mathrm{Cu}(\mathrm{II}) \mathrm{OEP}$ and $\mathrm{GC}+\mathrm{Cu}(\mathrm{II}) \mathrm{OEP}$ at buffer phosphate solution, $\mathrm{pH}$ $7.0\left(\right.$ scan rate $\left.=5 \mathrm{mVs}^{-1}\right)$. Amount of porphyrin deposited on each system.

\begin{tabular}{ccc}
\hline System & $\begin{array}{c}\text { Tafel slope value } \\
(\mathbf{m V} \text { per decade })\end{array}$ & $\begin{array}{c}\text { Amount of M-OEP } \\
\text { deposited (mol) }\end{array}$ \\
\hline $\mathrm{GC}+4 \mathrm{AP}+\mathrm{Co}(\mathrm{II}) \mathrm{OEP}$ & 194 & $4.86 \times 10^{-8}$ \\
$\mathrm{GC} \mathrm{ox}+\mathrm{Cu}(\mathrm{II}) \mathrm{OEP}$ & 103 & $5.22 \times 10^{-8}$ \\
$\mathrm{GC}+\mathrm{Cu}(\mathrm{II}) \mathrm{OEP}$ & 90 & $3.65 \times 10^{-8}$ \\
\hline
\end{tabular}




\subsection{Efficiency studies}

During steady-state electrolysis, the generation of bubbles on both sides of the cell was observed, which gives evidence of $\mathrm{H}_{2}$ production on the GCE and $\mathrm{O}_{2}$ production at the counter electrode. The results of this experiment are presented in Figure 3. Over a $4 \mathrm{~h}$ electrolysis period, we found that the GC $+4 \mathrm{AP}+\mathrm{Co}(\mathrm{II}) \mathrm{OEP}$ system is the most active one with respect to $\mathrm{H}_{2}$ production (Figure 3). This result was not expected since cyclic voltammetry showed a better response with the $\mathrm{GC}$ ox $+\mathrm{Cu}(\mathrm{II}) \mathrm{OEP}$ system (Figure 1). To explain this result, it is important to consider that voltammetry reports on the system behavior on short timescales and thus, electrolysis results should be compared at shorter periods of time. By considering this, we observed that the $\mathrm{GC}$ ox $+\mathrm{Cu}$ (II)OEP system is the most efficient only in the first 100 seconds (figure 3 ).

By integrating the charge passed in these systems, it is possible to determine the Faradaic efficiency, turnover number, and overpotentials, which compare favorably to systems previously reported $[15,16,25,26]$. In this sense, Hung and co-workers reported a system modified with a water-soluble anionic cobalt(II) tetrakis(p-sulfonatophenyl)porphyrin (CoTPPS), previously synthesized [27]. Although this system has a high efficiency towards her at neutral $\mathrm{pH}$, in this present work we have found that is possible to obtain as stable and efficient systems using commercial metalloporphyrins (M-OEP) adsorbed onto GC electrodes previously modified with anchoring groups. These novel systems are capable to reduce protons at low overpotentials at neutral $\mathrm{pH}$, with comparable TONs. This result is due to the generation of a supramolecular system which possesses a synergic effect that means, they have a great electrocatalytic effect in comparison to the bare electrode and their monomers themselves. Then, if a monolayer is active, as the one demonstered by Hung et al [27], it would be posible to obtain a more active system.

Finally, in order to evaluate the efficiency of the catalytic systems. Tables 2 and 3 show the results obtained by gas chromatography.

Table 2. Quantification of total amount of $\mathrm{H}_{2}$ produced by generated systems.

\begin{tabular}{ccccc}
\hline System & Peak area & $\begin{array}{c}\text { Total } \mathbf{H}_{2} \\
\text { produced }\end{array}$ & $\begin{array}{c}\text { Total } \mathbf{H}_{2} \text { produced per } \\
\text { time }\end{array}$ & $\begin{array}{c}\text { Total } \mathbf{H}_{2} \text { produced per time } \\
\text { and area }\end{array}$ \\
& $(\mathbf{m V s})$ & $(\mu \mathbf{m o l})$ & $\left(\mu \mathbf{m o l} \cdot \mathbf{h}^{-1}\right)$ & $\left.\mathbf{h}^{-1} \cdot \mathbf{c m}^{-2}\right)$ \\
\hline $\mathbf{G C}$ & 3.3 & 21.2 & 5.3 & 3.1 \\
$\begin{array}{c}\mathbf{G C ~ o x}+ \\
\mathbf{C u}(\mathbf{I I}) \mathbf{O E P}\end{array}$ & 616.0 & 169.8 & 42.5 & 25.0 \\
$\begin{array}{c}\mathbf{G C}+ \\
\mathbf{C u}(\mathbf{I I}) \mathbf{O E P}\end{array}$ & 892.8 & 237.0 & 59.3 & 34.9 \\
$\begin{array}{c}\mathbf{G C}+\mathbf{4 A P}+ \\
\mathbf{C o}(\mathbf{I I}) \mathbf{O E P}\end{array}$ & 1207.8 & 313.4 & 78.4 & 46.1 \\
\hline
\end{tabular}


Table 3. Obtained charge over 4-h electrolysis with generated systems and their corresponding faradaic efficiencies ${ }^{\mathrm{a}}$.

\begin{tabular}{cccc}
\hline System & $\boldsymbol{q}^{[\mathrm{b}]} / \boldsymbol{C}$ & $\boldsymbol{f}^{[\mathrm{cl} /} \%$ & TON $^{[\mathrm{d}]}$ \\
\hline $\mathbf{G C}$ & 7 & 58 & - \\
$\begin{array}{c}\text { GC ox }+ \\
\mathbf{C u}(\mathrm{II}) \mathbf{O E P}\end{array}$ & 55 & 61 & $3.3 \times 10^{3}$ \\
$\mathbf{G C}+\mathbf{C u}(\mathrm{II}) \mathbf{O E P}$ & 80 & 58 & $6.5 \times 10^{3}$ \\
$\begin{array}{c}\text { GC + 4AP + } \\
\mathbf{C o}(\mathrm{II}) \mathbf{O E P}\end{array}$ & 102 & 60 & $6.4 \times 10^{3}$ \\
\hline
\end{tabular}

[a] All experiments were done twice at $-1100 \mathrm{mV}$ vs $\mathrm{Ag} / \mathrm{AgCl}$ (average showed), [b] total amount of charge obtained, [c] faradaic efficiencies determined by gas chromatography and [d] turnover number calculated with total amount of hydrogen produced by moles of electrocatalyst.

The GC $+4 \mathrm{AP}+\mathrm{Co}(\mathrm{II}) \mathrm{OEP}$ modified system is the one that generates more charge over $4 \mathrm{~h}$ electrolysis, with a faradaic efficiency of $60 \%$, which corresponds to 6,400 turnovers of the catalyst. The other systems have a similar efficiency, and their TONs are similar or lower (GC ox $+\mathrm{Cu}(\mathrm{II}) \mathrm{OEP})$. These results give evidence of the electroreduction of water to hydrogen, but at lower rates. Additionally, in all electrolysis experiments, the current was constant, which indicates that the electrocatalyst is stable under these conditions. An example of this behavior is shown in figure 4, where the system is shown to be stable by applying a negative fixed potential for several minutes.

This last result is consistent with voltammetric profiles obtained after 10 cycles (figure 1).

\subsection{Morphological studies}

AFM studies were performed in order to analyze morphological changes on carbon surfaces. Figure 5 illustrates the images obtained. The AFM images support the idea that the covalent bond is important for generating molecular stacks on the carbon surface, since the direct deposition of the metalloporphyrin shows a different morphology that keeps the surface relatively flat. This effect can be corroborated by comparing the $R q$ values obtained in this study, which are showed in table 4 and which stand for root-mean-square roughness (RMS). 
Table 4. $R q$ values corresponding to the bare GC and modified GC electrodes

\begin{tabular}{cc}
\hline System & Rq value (nm) \\
\hline GC & 2.54 \\
$\mathbf{G C ~} \mathbf{0 x}$ & 19.6 \\
$\mathbf{G C}+\mathbf{4 A P}$ & 177 \\
$\mathbf{G C}+\mathbf{A P}+\mathbf{C o}(\mathrm{II}) \mathbf{O E P}$ & 55 \\
$\mathbf{G C} \mathbf{~ 0 x}+\mathbf{C u}(\mathbf{I I}) \mathbf{O E P}$ & 38.3 \\
$\mathbf{G C}+\mathbf{C u}(\mathbf{I I}) \mathbf{O E P}$ & 16.8 \\
\hline
\end{tabular}

Since $R q$ is the standard deviation of the height, it describes the spread of the height distribution about the mean value $[28,29]$. SEM studies were performed as well, with the aim of corroborate the morphological behavior of the samples. For each modified electrode, figure 5 shows its corresponding SEM image.

it is known, the surface chemistry of $\mathrm{sp}^{2}$ carbon materials is governed by basal and edge carbon atoms [30,31], as well as by the presence of defects (i.e., structural carbon vacancies, non-aromatic rings) [32], then, heteroatoms, such as oxygen and nitrogen, can be chemisorbed, leading to stable surface compounds, and resulting in a complex surface chemistry. This last effect is obtained once the carbon electrode is modified with covalent bonds, and so they can act as new active sites for porphyrin deposition (figure $5 \mathrm{~b}$ and $5 \mathrm{c}$ ).

However, it can be seen that still the chemiadsorption of $\mathrm{Cu}$ (II)OEP is achieved without using a covalent bond (figure 5d). This is a result of the nature of porphyrins (and other macrocycles), which are capable of forming $\pi$ interactions with carbon by their own. Though this direct deposition might affect the electronic properties of the $\mathrm{Cu}(\mathrm{II})$ porphyrin, the advantage is that this synthetic strategy does not require any prior chemical modification [33].

Figure 6 shows images corresponding to the modified electrodes and the comparison between methods of modification. There are obvious differences between the samples modified by immersion and those modified by reflux, which are the responsible of the electrocatalitic response towards her. In this sense, the refluxed systems can give a different morphology of the entire system that helps to carry the electron transfer out.

\subsection{Structural studies: Raman spectroscopy}

Raman spectra were obtained to study the linkage between the electrode, oxidized groups, the 4AP molecule, and metalloporhyrins. In this study, gold and graphene electrodes were used with the aim of obtaining better responses by using the Raman technique. The electrodes were modified as was done for glassy carbon electrodes, and the modifications were corroborated by electrochemical responses.

Molecular vibrations of the four-coordinate planar metalloporphyrins are classified into the in-plane and outplane modes, in which $\mathrm{A}_{1 \mathrm{~g}}, \mathrm{~B}_{1 \mathrm{~g}}, \mathrm{~B}_{2 \mathrm{~g}}$ and $\mathrm{E}_{\mathrm{g}}$ modes are Raman active. However, in resonance with $\mathrm{B}_{0}$ and $\mathrm{Q}_{0}$ bands, these modes are expected to gain Raman intensity [34]. 
Also, it is possible to consider the Raman spectra for modified electrodes with covalent bonds. At this point, oxidized groups can be recognized at 1034 and $576 \mathrm{~cm}^{-1}$ [35] and chemisorbed pyridine [36] gives their corresponding frequencies as shown in table 5. These modifications enable the linkage to the gold electrodes, by acting as new active sites. It is possible to observe the differences between spectra obtained with the anchoring molecule only and spectra obtained after the metalloporhyrin deposition. These latter spectra show characteristic frequencies for metalloporphyrins (table 5), but also, it is possible to recognize that there are shifts occurring at Raman frequencies by comparing the systems obtained by immersion and reflux. This provides additional evidence that there are structural differences between films prepared by the two methods.

For supramolecular systems obtained in this study (and the pure reagents as well), the totally symmetric C-C stretching mode appears around $1475-1510 \mathrm{~cm}^{-1}$. The peak around $1360-1375 \mathrm{~cm}^{-1}$ is attributed to the totally symmetric $\mathrm{C}-\mathrm{N}$ stretching mode and this band may be referred to reflect $\pi$ delocalization; as the extent of the $\mathrm{d}_{\pi}$ electrons to the LUMO of the porphyrin increases, its frequency decreases [37,38]. Due to the metalaxial ligand interactions, some Raman bands are affected. In this sense, C-N interactions are important in order to recognize the metal-axial ligand coordination. The stronger the Metal-N(pyrrole) bond, the shorter distance between the center of the porphyrin and the $\mathrm{N}$ (pyrrole) and the higher the ring stretching frequencies. When an axial ligand of the metalloporphyrin is occupied, a repulsive interaction between the ligand and pyrrole nitrogens occur which correspond to the repulsive interaction between the $\mathrm{d}_{\mathrm{x}}{ }^{2}-\mathrm{d}_{\mathrm{y}}{ }^{2}$ (metal) and $2 \mathrm{p}_{\mathrm{x}, \mathrm{y}}(\mathrm{N})$ orbitals [39]. Finally, it is possible to compare the pure reagent spectra with the results obtained in figure 7. $\mathrm{C}-\mathrm{N}$ interactions appear around $1390 \mathrm{~cm}^{-1}$ and $1406 \mathrm{~cm}^{-1}$ (non-shown) for $\mathrm{Cu}$ (II)OEP and Co(II)OEP pure reagents, respectively. These latter results give evidence that the change of the $\mathrm{C}-\mathrm{N}$ frequency in supramolecular systems is a result of coordination between the porphyrin and the covalently bound molecule on the electrode surface. Finally, figure 8 shows results obtained for graphene electrodes, which also present a good electroactivity and stability towards her when these substrates are modified to generate supramolecular systems as the ones presented here (figure S5, Supporting Information).

With these results, it is possible to corroborate the generation of supramolecular systems, which imply an electrodic substrate (GC), the existence of an anchoring group and the coordination of metalloporphyrins through the metallic center. This system finally possesses a high stability due to the generation of a covalent bond previous to the porphyrin deposition, and with high efficiency towards hydrogen production.

Here, there is evidence of the modification of the graphene monolayers with the supramolecular catalysts. 
Table 5. Raman assignments for different systems $(\alpha=$ in plane bends, $\gamma=$ out of plane bend, $v=$ stretch, $\delta=$ deformation vibration about the $\mathrm{C}_{2}$ axis of pyrrole ring)

\begin{tabular}{|c|c|c|}
\hline System & Raman shift $/ \mathrm{cm}^{-1}$ & Assignment \\
\hline & 1034 & $v(\mathrm{O}-\mathrm{O})$ \\
\hline Au-ox & 576 & $v(\mathrm{O}-\mathrm{H})$ \\
\hline \multirow{5}{*}{$A \mathbf{u}+4 \mathbf{A P}$} & 1792 & $v(\mathrm{C}-\mathrm{C})$ \\
\hline & 1006 & $\alpha(\mathrm{C}-\mathrm{C}-\mathrm{C}), v(\mathrm{C}-\mathrm{C})$ \\
\hline & 850 & $\gamma(\mathrm{C}-\mathrm{H})$ \\
\hline & 746 & Ring bend \\
\hline & 565 & $\alpha(\mathrm{C}-\mathrm{C}-\mathrm{C})$ \\
\hline \multirow{5}{*}{$\mathbf{A u}+\mathbf{C u}(\mathrm{II}) \mathrm{OEP}(\mathrm{In})$} & 3026 & $v(\mathrm{C}-\mathrm{H})$ \\
\hline & 2958 & $v(\mathrm{C}-\mathrm{H})$ \\
\hline & 1424 & $v(\mathrm{C}-\mathrm{C}), v(\mathrm{C}-\mathrm{Et})$ \\
\hline & 1223 & $\delta(\mathrm{C}-\mathrm{H}), v(\mathrm{C}-\mathrm{Et})$ \\
\hline & 1379 & $v(\mathrm{C}-\mathrm{N}), \delta(\mathrm{C}-\mathrm{C})$ \\
\hline \multirow{7}{*}{$\mathrm{Au}+\mathrm{Cu}(\mathrm{II}) \mathrm{OEP}(\mathrm{R})$} & 3782 & $v(\mathrm{C}-\mathrm{H})$ \\
\hline & 3568 & $v(\mathrm{C}-\mathrm{H})$ \\
\hline & 3015 & $v(\mathrm{C}-\mathrm{H})$ \\
\hline & 2947,2823 & $v(\mathrm{C}-\mathrm{H})$ \\
\hline & 1436 & $v(\mathrm{C}-\mathrm{C}), v(\mathrm{C}-\mathrm{Et})$ \\
\hline & 1210 & $\delta(\mathrm{C}-\mathrm{H}), v(\mathrm{C}-\mathrm{Et})$ \\
\hline & 1368 & $v(\mathrm{C}-\mathrm{N}), \delta(\mathrm{C}-\mathrm{C})$ \\
\hline \multirow[b]{3}{*}{ Au ox + Cu(II)OEP (In) } & 1421 & $v(\mathrm{C}-\mathrm{C}), \quad v(\mathrm{C}-\mathrm{Et})$ \\
\hline & 1376 & $v(\mathrm{C}-\mathrm{N}), \delta(\mathrm{C}-\mathrm{C})$ \\
\hline & 1143 & $v(\mathrm{C}-\mathrm{N}), \delta(\mathrm{C}-\mathrm{Et})$ \\
\hline \multirow[b]{3}{*}{ Au ox + Cu(II)OEP (R) } & 1424 & $v(\mathrm{C}-\mathrm{C}), \quad v(\mathrm{C}-\mathrm{Et})$ \\
\hline & 1368 & $v(\mathrm{C}-\mathrm{N}), \delta(\mathrm{C}-\mathrm{C})$ \\
\hline & 1154 & $v(\mathrm{C}-\mathrm{N}), \delta(\mathrm{C}-\mathrm{Et})$ \\
\hline \multirow{5}{*}{$\mathrm{Au}+4 \mathrm{AP}+\mathrm{Co}(\mathrm{II}) \mathrm{OEP}$ (In) } & 3004 & $v(\mathrm{C}-\mathrm{H})$ \\
\hline & 1413 & $v(\mathrm{C}-\mathrm{C}), \quad v(\mathrm{C}-\mathrm{Et})$ \\
\hline & 1378 & $v(\mathrm{C}-\mathrm{N}), \delta(\mathrm{C}-\mathrm{C})$ \\
\hline & 1223 & $\delta(\mathrm{C}-\mathrm{H}), v(\mathrm{C}-\mathrm{Et})$ \\
\hline & 1143 & $v(\mathrm{C}-\mathrm{N}), \delta(\mathrm{C}-\mathrm{Et})$ \\
\hline \multirow{5}{*}{$\mathrm{Au}+4 \mathrm{AP}+\mathrm{Co}(\mathrm{II}) \mathrm{OEP}(\mathrm{R})$} & 3050 & $v(\mathrm{C}-\mathrm{H})$ \\
\hline & 1426 & $v(\mathrm{C}-\mathrm{C}), \quad v(\mathrm{C}-\mathrm{Et})$ \\
\hline & 1402 & $v(\mathrm{C}-\mathrm{N}), \delta(\mathrm{C}-\mathrm{C})$ \\
\hline & 1210 & $\delta(\mathrm{C}-\mathrm{H}), v(\mathrm{C}-\mathrm{Et})$ \\
\hline & 1143 & $v(\mathrm{C}-\mathrm{N}), \delta(\mathrm{C}-\mathrm{Et})$ \\
\hline
\end{tabular}




\section{CONCLUSIONS}

The generated systems with covalent bonds and direct deposition via reflux behave as good electrocatalysts towards her and are highly efficient in comparison to other reported systems with similar molecular structures. This effect is attributed to the supramolecular structure of the electrode films, which facilitates the diffusion of reactants and products and the charge transfer processes. AFM and SEM studies show how the morphological behavior changes when different methods of modification are applied (immersion and reflux) and also, when covalent bonds are formed at the electrode surface prior to porphyrin deposition. Finally, Raman studies prove the existence of covalent bonds and the formation of supramolecular complexes on gold and graphene electrode surfaces, which are consistent with the electrocatalytic activity of the films towards her.

\section{ACKNOWLEDGEMENTS}

The authors would like to acknowledge the financial support provided by FONDECYT Project No.: 1120049 and No.: 1141199, Doctoral Scholarship CONICYT Project No.: 21140095 and Project RC 130006, CILIS.

TEM acknowledges support from the Office of Basic Energy Sciences, Division of Chemical Sciences, Geosciences, and Energy Biosciences, Department of Energy under contract DE-FG02-07ER15911

\section{REFERENCES}

[1] D.A.J. Rand, J. Solid State Electrochem. 15 (2011) 1579-1622

[2] R. Everett, G. Boyle, S. Peake, J. Ramage, Energy systems and sustainability: power for a sustainable future. Oxford Univerity Press, 2012.

[3] S.P.S. Badwal, S.S. Giddey, C. Munnings, A.I. Bhatt, A.F. Hollenkamp, Front. Chem. 2014, 2, 79

[4] C.G. Morales-Guio, L.-A. Stern, X. Hu, Chem. Soc. Rev. 43 (2014) 6555-6569

[5] X. Chen, D. Wang, Z. Wang, P. Zhou, Z. Wu, F. Jiang, Chem. Commun. 50 (2014) 11683-11685

[6] J. Deng, P. Ren, D. Deng, L. Yu, F. Yang, X. Bao, Energy Environ. Sci. 7 (2014) 1919-1923

[7] D. Wang, J.T. Groves, PNAS 110 (2013) 15579-15584

[8] F.J. Callejas, J.M. McEnaney, C.G. Read, J.C. Crompton, A.J. Biacchi, E.J. Popczun, T.R. Gordon, N.S. Lewis, R.E. Schaak, ACS Nano 8 (2014) 11101-11107

[9] P. Jiang, Q. Liu, Y. Liang, J. Tian, A.M. Asiri, X. Sun, Angew. Chem. Int. Ed. 53 (2014) 1-6

[10] A. Krawicz, J. Yang, E. Anzenberg, J. Yano, I.D. Sharp, G.F. Moore, J. Am. Chem. Soc. 135 (2013) 11861-11868

[11] X. Wang, Y.V. Kolenko, L. Liu, Chem. Commun. 51 (2015) 6738-6741

[12] J.H. Zagal, F. Bedioui, J-P. Dodelet, $\mathrm{N}_{4}$ - Macrocyclic Metal Complexes, Springer Science - Business Media LLC, New York, 2006

[13] X. Hu, B.S. Brunschwig, J.C. Peters, J. Am. Chem. Soc. 129 (2007) 8988-8998

[14] X. Hu, B.M. Crossairt, B.S. Brunschwig, N.S. Lewis, J.C. Peters, Chem. Commun. 37 (2005) 4723-4725

[15] C.C.L. McCrory, C. Uyeda, J.C. Peters, J. Am. Chem. Soc. 134 (2012) 3164-3170

[16] A. Koca, Electrochem. Commun. 11 (2009) 838-841

[17] C. Canales, L. Gidi, G. Ramírez, Int. J. Electrochem. Sci. 10 (2015) 1684-1695

[18] T. Atogushi, A. Aramata, A. Kazusaka, M. Enyo, J. Electroanal. Chem. 318 (1991) 309-320

[19] G. Ramírez, G. Ferraudi, Y.-Y. Chen, E. Trollund, D. Villagra, Inorg. Chim. Acta 362 (2009) 5-10

[20] C.C. Vaduva, N. Vaszilcsin, A. Kellenberger, M. Medeleanu, Int. J. Hydrogen Energ. 36 (2011) 69947001

[21] G. Ramírez, M. Lucero, A. Riquelme, M. Villagrán, J. Costamagna, E. Trollund, M.J. Aguirre, J. Coord. Chem. 57 (2004) 249-255 
[22] N. Navarrete, C. Canales, R. Del Rio, G. Ramírez, J. Chil. Chem. Soc. 58 (2013) 1971-1975

[23] D. Voiry, H. Yamaguchi, J. Li, R. Silva, D.C.B. Alves, T. Fujita, M. Chen, T. Asefa, V.B. Shenoy, G. Eda, M. Chhowalla, Nature mater. 12 (2012) 850-855

[24] A. Lasia, A. Rami, J. Electroanal. Chem. 294 (1990) 123-141

[25] A.N. Frumkin, Hydrogen overvoltage and adsorption phenomena In: Advances in Electrochemistry and Electrochemical Engineering, P. Delahay, C.W. Tobias, editors, vol. 3. New York: Interscience Publishers Inc; 1963. pp. $65-122$.

[26] P.V. Bernhardt, L.A. Jones, Inorg. Chem. 38 (1999) 5086-5090

[27] B.B. Beyene, S.B. Manea, C.-H. Hung, Chem. Commun. 51 (2015) 15067-15070

[28] H. Wenhao, C. Yuhang, J. Phys. Conf. Ser. 13 (2005) 44-50

[29] C. Canales, G. Ramírez, Electrochim. Acta 173 (2015) 636-641

[30] L.R. Radovic, B. Bockrath, J. Am. Chem. Soc. 127 (2015) 5917-5927

[31|] M. Acik, Y.J. Chabal, Jpn. J. Appl. Phys. 50 (2011) 070101

[32] F. Banhart, J. Kotakoski, A.V. Krasheninnikov, ACS Nano 5 (2010) 26-41

[33] M.R. Axet, O. Dechy-Cabaret, J. Durand, M. Gouygou, P. Serp, Coord. Chem. Rev., 2015, doi:10.1016/j.ccr.2015.06.005

[34] J.W. Buchler, Metal Complexes with Tetrapyrrole Ligands I, Structure and Bonding. In: Infrared and Raman spectra of metalloporphyrins, T. Kitagawa, Y. Ozaki, editors. vol. 64. Springer Berlin Heidelberg; 1987. pp. $71-114$.

[35] P.J. Murphy, G. Stevens, M.S. Lagrange, Geochim. Cosmochim. Acta 64 (2000) 479-494

[36] M. Fleischmann, I.R. Hill, J. Electroanal. Chem. 146 (1983) 353-365

[37] T.G. Spiro, T.C. Strekas, J. Am. Chem. Soc. 96 (1974) 338-345

[38] T. Kitagawa, T. Iizuka, M. Saito, Y. Kyogoku, Chem. Lett. 4 (1975) 849-852

[39] J. Kincaid, K.J. Nakamoto, Inorg. Nucl. Chem. 37 (1975) 85-89 